This is the peer reviewed version of the following article:

Jonauskaite, D., Althaus, B., Dael, N., Dan-Glauser, E. S., \& Mohr, C. (2019). What color do you feel? Color choices are driven by mood. Color Research \& Application, 44(2), 272-284. http://dx.doi.org/10.1002/col.22327

It has been published in final form at http://dx.doi.org/10.1002/col.22327. This article may be used for non-commercial purposes in accordance with Wiley Terms and Conditions for Use of Self-Archived Versions. 


\section{What colour do you feel? Colour choices are driven by felt mood}

Domicele Jonauskaite, Betty Althaus, Nele Dael, Elise Dan-Glauser, and Christine Mohr

Institute of Psychology, University of Lausanne, Lausanne, Switzerland

\section{Corresponding author:}

Domicele Jonauskaite

Institute of Psychology

University of Lausanne

Quartier Mouline, Bâtiment Géopolis

CH-1015, Lausanne, Switzerland

+41216923252

Domicele.Jonauskaite@unil.ch

ORCID ID: 0000-0002-7513-9766 


\begin{abstract}
Popular opinion holds that color has specific affective meaning. Brighter, more chromatic, and warm colors were conceptually linked to positive stimuli and darker, less chromatic, and cool colors to negative stimuli. Whether such systematic color associations exist with actually felt mood remains to be tested. We experimentally induced four moods-joy, relaxation, fear, and sadness-in a between-subject design ( $N=96)$. Subsequently, we asked participants to select a color, from an unrestricted sample, best representing their current mood. Color choices differed between moods on hue, lightness, and chroma. Yellow hues were systematically associated with joy while yellowgreen hues with relaxation. Lighter colors were matched to joy and relaxation (positive moods) than fear and sadness (negative moods). Most chromatic colors were matched to joy, then relaxation, fear, and sadness. We conclude that color choices represent felt mood to some extent, after accounting for a relatively low specificity for color-mood associations.
\end{abstract}

Keywords: mood induction, music, emotion, affective science, cognitive psychology, Geneva Emotion Wheel 


\section{Acknowledgements}

This research was made possible thanks to the support of the Swiss National Science Foundation, providing a Doc.CH fellowship grant to DJ (POLAP1_175055). We thank Dr. Jean-Philippe Antonietti, Cornelis B. Doorenbos and Dr. Guillaume Sierro for statistical support. We wish to thank AkzoNobel, Imperial Chemical Industries (ICI) Limited, in particular Dr. David Elliott, Dr. Tom Curwen and Peter Spiers, Colour R\&I team, Slough, the United Kingdom, and Stephanie Kraneveld, Sassenheim, the Netherlands, for supporting our empirical work on colours and emotions. No conflicts of interest are declared. 
The Internet is flourishing with websites claiming that a person's mood, emotion or personality can be inferred from his or her colour choices. For example, people who like red are supposed to be "action oriented"1, "active, cheerful, and optimistic" and their driving force is "power" "competitiveness and desire"4. People who like yellow have a "logical mind"1, they are "perfectionists or dreamers"2, "fun" ${ }^{3}$, and "spontaneous and active" ${ }^{4}$. The Lüscher Colour Test ${ }^{4}$ attempts to describe peoples' personalities and motivations based on their preference ranking of eight colours. Despite low construct validity ${ }^{5-7}$, the test has been widely applied to interpret respondents' internal thoughts and feelings ${ }^{8-10}$. All these materials are based on the assumption that colour choices are indicative of one's internal states. However, few empirical studies have been conducted on this matter (but see ${ }^{11-15}$ ). Before being able to make any inferences on others' internal states based on their colour choices, it is crucial to empirically demonstrate that there is a systematic and reliable association between one's current affective state (mood) and a colour matched to represent it.

The majority of research studies in the colour psychology field focused on how colour conceptually relates to emotions or affective dimensions. In the seminal paper, Valdez and Mehrabian (1994) investigated how evoked affective responses to physical colours were rated along affective dimensions of valence (e.g., pleasant - unpleasant; affectionate - nasty), arousal (e.g., exiting calming; frustrated - sad), and dominance (e.g., dominant - submissive; violent - fearful). The relationship between colour dimensions and affective dimensions was non-linear. Brighter and more chromatic colours were rated as more pleasant; darker and more chromatic colours were rated as more arousing; and darker and more saturated colours were rated as more dominant. Similar associations have been reported in other studies using physical colour samples ${ }^{17}$ and colour concepts $^{18,19}$. These associations between colour dimensions and emotion dimensions seem to hold cross-culturally with, for example, lighter colours being evaluated as more positive than darker 
colours ${ }^{20,21}$. Other lines of research focused on colour associations with more specific discrete emotions. For example, in a perceptual study ${ }^{22}$, participants matched self-selected colours to bodily expressions of two high arousal emotions opposite in valence (elated joy, panic fear). The positive expressions of elated joy were matched to bright, chromatic and red-yellow hues. The negative expressions of panic fear were matched to dark, low chromatic and cyan-blue hues. In another study ${ }^{23}$, yellow and red (of medium lightness) were chosen as "mood enhancing" while purple, blue, and orange (all light) as "calming". Colour associations with discrete emotions may vary more strongly across cultures though. For example, colour associations with envy depended on one's mother tongue as envy has been associated with yellow, red, green, black, or purple ${ }^{24}$. Taken together, colours seem to be systematically associated with emotions when participants evaluate such associations conceptually.

Less is known whether the same colour-affect associations hold when colour is matched to current moods. This knowledge is crucial to be able to eventually estimate other people's moods from their colour choices. Several previous studies demonstrated that colour matches to one's general mood differed between healthy and clinical populations. Carruthers and colleagues ${ }^{11}$ asked healthy participants and participants with mood disorders (i.e., depressed or anxious) to match their current mood to 38 pre-selected colours. The majority of healthy participants matched their mood to a bright shade of yellow (or another bright colour). The majority of clinically anxious or depressed participants matched their current mood to various shades of grey. Similarly, healthy children predominantly associated their mood to bright yellow, while clinically depressed children associated their mood with black ${ }^{13}$. These results are in line with previous reports linking depression to dark colour choices (i.e., black and brown ${ }^{15}$ ). Taken together, these studies empirically demonstrated that clinical moods are matched to different colours compared to non-clinical moods, indicating that affective experience (mood) is systematically associated with colour. 
The latter studies opened up research avenues to investigate colour associations with more specific moods in non-clinical populations. Since participants of the previous studies ${ }^{11-13,15}$ did not specify their current moods, it is unclear what exact mood their colour matches represented. To further understand how colour choices more immediately interact with affective functions in a general population and how precise affectively driven colour matches are, an experimental paradigm can be useful to assess causal relationships between induced mood and colour choices. Mood can experimentally be induced using numerous techniques, such as showing affective images ${ }^{25}$ or film extracts $^{26}$, activating relevant affective expressions ${ }^{27}$ or relevant autobiographical memories ${ }^{28}$, or listening to music ${ }^{29}$. Listening to music affects people's emotional states ${ }^{30}$, but can be considered ambiguous in terms of its emotional content ${ }^{31}$ and not communicate discrete emotions ${ }^{32}$. For example, "sad" music can be experienced as sad as well as pleasurable ${ }^{33-37}$. When music is contextualised (e.g., with lyrics, mental imagery), the emotional ambiguity is reduced, and it becomes one of the most powerful and widely used techniques for mood induction ${ }^{38-40}$. In such a mixed technique, participants listen to music and read short stories, which they are asked to actively imagine $^{41}$. This procedure has been effective for inducing joy, sadness, fear, anger ${ }^{42-44}$, and relaxation ${ }^{45}$.

Music alone has been cross-modally linked with colours. Music with faster tempo and in major mode (rated as "happy" music) was matched to more saturated, lighter, and yellower colours compared to music with slower tempo and minor mode (rated as "sad" music), which was matched to less saturated, darker, and bluer colours from a sample of 37 colours ${ }^{46,47}$. Similar results were obtained when colour selection was unrestricted: music expressing joy was linked to yellow, anger to red, and sadness to dark, blue colours ${ }^{48}$. In another study, positively valenced music was represented with brighter colours than negatively valenced usic $^{49}$. It has been argued that the systematic link between music and colours is to be mediated by emotions ${ }^{46}$. Considering that music evokes 
emotions and systematically associates with colours, music is thus a good medium to use in order to assess colour associations with induced mood.

Taken together, music acts as a tool for mood induction ${ }^{41}$ and shows systematic associations with colour $^{46,48,49}$, potentially mediated by its affective content ${ }^{46,48}$. Exposure to colour is associated with affective responses ${ }^{16,23}$. In the other direction, colour choices seem to be linked to general moods ${ }^{11-}$ 13,15. There is, however, no empirical evidence confirming that actually felt affective states (i.e., moods) influence subsequent colour choice behaviour. Such results would facilitate inferences about others' moods and provide causal evidence for colour-affect associations. Here, we systematically assessed colours matched to induced joy, relaxation, fear, and sadness ${ }^{41,50}$. We chose these moods since they differentially loaded on valence and arousal dimensions ${ }^{51}$. Immediately after the mood induction, participants matched the colour that represented their current mood using an intuitive unrestricted colour-selection procedure (Fig 1, A-E). Instead of using a pre-selected sample of colours (similar to $4,11,15,16,20,23,46$ ), we opted for an unrestricted colour range (similar to ${ }^{22,48}$ ) since we had no a priori expectations of which colours would be most relevant to this task. We believe that unrestricted exploration and choice of colour gives the largest degree of freedom to participants and provides the most honest representation of colour-affect associations.

We analysed colour matches based on the three colour dimensions: hue, lightness, and chroma ${ }^{52}$. Hue is what laypeople refer to as colour (e.g., red, blue, yellow, etc.); chroma defines the colour "purity" - colours with low chroma appear greyish and dull; lightness defines how light the colour is. Regarding hue, we expected yellow hue to be chosen for joy $22,23,46,48$ and blue hue for relaxation ${ }^{23}$, fear ${ }^{22}$, and sadness ${ }^{46,48}$. Regarding lightness, we expected lighter colours to be matched to positive affective states (i.e., joy and relaxation) $)^{16,20,22,49}$ and that lightness of the matched colours may vary by arousal ${ }^{16}$. Regarding chroma, we expected more chromatic colours to be matched to both positive (i.e., joy and relaxation) and arousing (i.e., fear and joy) affective states ${ }^{16,22,23}$. 


\section{Method}

\section{Participants}

We recruited 125 first year psychology students ( 25 males) with a mean age (always in years) of $20.41(S D=2.91$, range 17 to 39$)$. Most participated in return for course credit. Two males were colour blind (tested with Ishihara colour blindness test ${ }^{53}$ ) and excluded from subsequent analyses. After the screening procedure (described below in the Affect manipulation check), 96 participants (17 males) with a mean age of 20.28 ( $S D=2.09$, range: 18 to 29 ) remained in the study. This sample size fulfilled the minimum recommendation of at least 20 participants in each condition ${ }^{54}$ and was sufficiently powered to detect an effect ${ }^{55}$. The experiment was conducted in accordance with the principles expressed in the Declaration of Helsinki and informed consent was collected from all the participants. According to the Swiss Law in the Canton of Vaud, no further ethical approval was required for the study.

\section{Material}

Mood induction with music and guided imagery: We used empirically validated ${ }^{41,56}$ material for five mood inductions: neutral baseline and four moods. The neutral baseline was induced by having participants read factual, non-emotional short stories without listening to any musical piece. The neural baseline was implemented to homogenise participants' mood upon arrival before the experiment started. This method was adapted from a previous study ${ }^{56,57}$ and it has been shown to be effective in inducing neutral mood ${ }^{58,59}$ (see Table 1 for English version and Table S1 for French version used in this study). As the original method did not feature music, we also performed it as such. The four moods - joy, relaxation, fear, and sadness - were induced in a between-subject design with the validated mixed mood induction technique ${ }^{41,45,50}$. Participants listened to pieces of 
music targeting one of the four moods and were guided by short stories to imagine different scenarios (Fig 1, A-E, see Table 1 for English version and Table S1 for French version used in this study). For example, during joy induction, participants were asked to imagine that they won at the lottery, among other scenarios, while listening to Coppélia by Delibes (1870; see Table 1 and Musical references in SI). The musical pieces and short stories were taken from previous research ${ }^{41,45,50}$.

[Insert Fig 1 around here]

[Insert Table 1 around here]

Colour selection - computerised colour picker: The computerised colour picker, used to match colour to induced affective states, works as follows (see Fig 1, D). Participants are asked to imagine a colour they want to choose (i.e., a target colour) and then use the colour picker to find this target colour. In the first step, participants see nine colour patches (red, orange, yellow, yellow-green, green, green-blue, blue, purple, and grey) on a white rectangle in the middle of the white screen. While this initial presentation is hue-based, the upcoming screens provide ample opportunity to choose colours according to lightness and chroma as well as hue. Participants are invited to click on the patch that most closely resembles their target colour (Fig 1, D.1). In the following screen, their chosen colour appears in the middle and is surrounded by eight variations of the chosen colour darker or lighter, more or less chromatic, yellower, bluer, greener, or redder (Fig 1, D.2). Participants are again invited to choose the colour which is the closest to the target colour. By clicking on the surrounding patches, participants can change lightness (choose a lighter or a darker colour), chroma (choose a more or less chromatic colour) and hue (make their colour more yellowish, bluish, greenish, or reddish) of the colour. If they make a wrong choice (e.g., erroneously choose a darker colour), they can correct their choice in the next screen (e.g., by choosing a lighter colour). Multiple routes exist in reaching the same target colour (e.g., a desired shade of purple can be found starting from red and making it bluer, or starting from blue and making it redder, or even via another less 
direct route). If a participant is content with the colour choice of the previous screen, they can select the same colour in the next screen. By doing so, they narrow down the difference between the central and the surrounding colour patches (Fig 1 D.2-D.4). In this way, participants can choose the exact shade of the target colour without having to make compromises if colour selection was more restricted. Participants can go through as many screens as needed to find the target colour: there is no fixed number of screens. Fig 1, D.1-D.6 displays only one of many possible routes. When the difference between the central and the surrounding patches becomes too low, the final patch is singled out. This colour appears as the only colour patch in the centre of the screen (Fig 1, D.5). At this point, participants can still click on the central patch, which would result in reappearance of the surrounding patches, and change or refine their colour choice. The final patch can be enlarged to fill the screen and verify the colour selection (Fig 1, D.6). The RGB values are presented on the screen together with the number of clicks taken to arrive at the final colour and the time it took from the first click to the final colour choice (also see ${ }^{60,61}$ and https://www2.unil.ch/onlinepsylab/ColourPicker/html/colorpicker.html).

Affect assessment - Geneva Emotion Wheel (GEW version 3.0 ${ }^{51,62}$ ): On the GEW, 20 emotions are presented in a circle (Fig 2 \& Fig 1, E). These emotions are organised along two emotion dimensions - valence (positive: right hand side; negative: left hand side) and dominance (high power/control: top; low power/control: bottom). In addition, circles of increasing size, mapped from the hub to the rim of the wheel, signify five degrees of intensities of these emotions. Options "No emotion" and "Different emotion" appear in the centre of the wheel. For the purpose of the current study, we exchanged relief, which originally featured on the GEW, with relaxation, one of the targeted moods. We chose relief, because both relief relaxation are positive emotions of low arousal and low dominance ${ }^{63}$. GEW was administered in paper-pencil format.

[Insert Fig 2 around here] 


\section{Procedure}

After signing the informed consent form, colour blindness was assessed using the 24-plate version of the Ishihara test ${ }^{53}$. Then, we explained the procedure and participants were guided into individual testing rooms for the behavioural experiment. Participants were seated approximately $70 \mathrm{~cm}$ from the monitor. There was no light source other than the monitor in the testing rooms.

The experiment started with setting a neutral baseline by having all participants read factual, nonemotional short stories ${ }^{57}$. Participants read the neutral short stories on a sheet of paper and were asked to imagine the short stories as vividly as possible (for examples consult Table 1). Afterwards, participants matched the most representative colour to their current mood using the colour picker (see Colour selection). They also indicated their most prominent current mood (i.e., before the mood induction) and rated the strength of this affective state using the Geneva Emotion Wheel with 20 emotions (see Affect assessment; Fig 2). Colour selection was completed before labelling the mood. We wanted to avoid the labelling dampening participants' affective experiences and influencing their colour selection ${ }^{64}$.

Then, in a between-subject design, we randomly assigned participants to one of the four mood induction conditions, and induced one of the four moods using music combined with short stories $^{41,45,50}$. In each case, participants listened to pieces of music for 4 minutes, and then, while continuing listening to music, were guided by short stories to imagine different scenarios (Fig 1, B-C). We pseudo-randomly assigned participants to joy, relaxation, fear, and sadness conditions. We planned to test four participants in each session and each participant was randomly assigned to a different mood induction condition. In some instances, fewer than four participants arrived to the testing session, and so the number of participants in each condition was uneven. Towards the end of the recruitment, we assigned participants to the conditions that were lacking participants to equalise groups. The final sample consisted of 33 participants in the joy condition, 29 in the 
relaxation condition, 30 in the sadness condition, and 29 in the fear condition. Participants started the experiment by reading the task instructions on the screen (Fig 1, A). They then listened to music on high quality around-ear Sennheiser headphones for four minutes, while the screen was set to black (Fig 1, B). Participants adjusted the headphones to their comfort and the volume was set to comfortable listening level (approximately 70dB).. After four minutes of listening to music, the volume of the music was halved and eight short stories sequentially appeared on the screen in white text on a black background (see Fig 1, C \& Table 1). The short stories changed every 30 seconds, which provided sufficient time to read them and imagine the stories. Participants were encouraged to imagine the stories portrayed in short stories as vividly as possible.

Immediately after the mood induction, participants used the colour picker (see Colour selection) to select the colour that best represented the mood they were feeling (i.e., post mood induction colour; Fig 1, D). Once the post mood induction colour was selected, participants used the paper version of the Geneva Emotion Wheel to indicate and rate the strength of the single most prominent mood they were feeling at that moment (i.e., after the mood induction; Fig 1, E \& Fig 2). This rating was later converted into the numeric scale from 1 (smallest circle, low intensity) to 5 (biggest circle, high intensity), or 0 if the mood had not been selected. The experiment took around 30 minutes. Participants were thanked and debriefed at the end of the experiment. After the debriefing, participants who received a negative (i.e., fear or sadness) mood induction during the experiment underwent a positive (i.e., joy or relaxation) mood induction of their choice.

\section{Data preparation}

Conversion of colour parameters: to have monitor-independent colour measurements, we converted the monitor-specific RGB values of participants' colour choice, into CIE-LCh colourimetric values (Commission Internationale de l'Eclairage, 1976) which a) can be compared across different testing situations (e.g. monitors) within and across studies, b) are perceptually uniform ${ }^{52}$. To achieve 
that, we used Konica Minolta CS-100A chroma meter to measure each selected colour. We then arithmetically converted obtained xyY values into CIE-Lab and then CIE-LCh values (see ${ }^{65}$ for formulae) by taking the maximum white of each monitor as reference white point. The final analyses were performed on CIE-LCh colour values.

Hue categorisation. The CIE-LCh colour parameters are hue, lightness, and chroma. Lightness and chroma are linear variables ranging from 0 to 100 (lightness) or 140 (chroma). Hue defines "colour family" (e.g., red, blue, green, etc.) and is a circular variable ranging from $0^{\circ}$ to 360 . Hue was analysed as a continuous circular variable as well as a categorical variable, in order to better understand the differences between the affective state conditions (see ${ }^{66}$ for a similar approach). For categorical analyses, hue angles were binned into perceptually-relevant categories ${ }^{60,67}$, making nine categories in total: red $\left(346^{\circ}-40^{\circ}\right)$, orange $\left(40^{\circ}-72^{\circ}\right)$, yellow $\left(72^{\circ}-105^{\circ}\right)$, yellow-green $\left(105^{\circ}-130^{\circ}\right)$, green $\left(130^{\circ}-166^{\circ}\right)$, green-blue $\left(166^{\circ}-220^{\circ}\right)$, blue $\left(220^{\circ}-275^{\circ}\right)$, purple $\left(275^{\circ}-346^{\circ}\right)$, and achromatic (i.e., grey ranging from white to black, defined as chroma less than 5 , any hue angle). The category of achromatic colours was defined by low chroma rather than hue, thus it is not a hue category per se. Nevertheless, it was included in these analyses to have a more accurate representation of colour selections. Hue discretization respected common perceptual boundaries. In Parraga and Akbarinia's study ${ }^{67}$, participants were presented with two neighbouring colour terms (e.g., green and blue) and manipulated the CIE Lab colour space until they found a colour that was exactly midway between the two given colour terms. This method of adjustment enabled the researchers to determine which colours lie on the boundaries of colour categories, and we were able infer perceptually relevant hue ranges. For additional hue analyses, we further grouped red, orange, yellow, and yellow-green hues as warm, and green-blue and blue hues as cool based on the notion that reddish-yellowish hues are considered warm and bluish hues are considered cool ${ }^{68}$. We did not include green and purple hues into warm and cool categories because these hues are located in the space between yellow and blue (i.e., green) or blue and red (i.e., purple) of the hue circle (e.g., Munsell system ${ }^{52}$ ). Thus, green and 
purple cannot be unambiguously categorised as either warm or cool hues. Since colour categorisation into warm and cool is mainly defined by hue ${ }^{68}$, achromatic colours were not included into this classification either.

Affect manipulation check: We verified whether the intended mood was successfully induced. We classified the GEW responses into congruent moods (match of valence and arousal levels to induced affective states) and incongruent moods (no match of valence or arousal levels to induced affective states). This classification was based on previous studies ${ }^{51,69,70}$. For example, if a participant selected amusement on the GEW as their current mood after the joy induction, this mood choice was classified as congruent. Both amusement and joy are positive and arousing emotions. If a participant selected contentment or sadness on the GEW after the joy induction, these mood choices were classified as incongruent. Contentment is a positive emotion of low arousal and sadness is a negative emotion of low arousal. These two emotions did not match on one or both emotion dimensions of the intended mood (in this example, joy). For all mood choices, please consult Table S2.

Participants were most likely to experience the mood that we had intended to induce compared to the other moods $\left(\chi^{2}=177.7, p<.001\right)$. They were also congruent in their mood choices: out of 20 affective states listed (in addition to the option "none" and "other"), 25 out of 29 participants (86\%) from the relaxation condition responded feeling precisely relaxation. The reported-induced state congruency was also high for the sadness ( 24 of 30 participants i.e., $80 \%$ ) and fear (25 of 29 participants, i.e., $86 \%$ ) conditions. In the joy condition, 22 of 33 participants (66\%) reported feeling joyful; the second most frequently reported felt state was relaxation (18.1\%) (see Table S2 for the reported felt affective states). To have a homogeneous sample of a felt mood in each mood induction condition, we excluded participants who did not report congruent moods ( $N=25,20 \%$ of total dataset). Fig S1 displays colours associated to the induced incongruent moods (i.e., colour matches by the participants excluded from the main analyses). The final analyses were performed on 96 participants (17 males), who experienced moods congruent to the induced moods (joy $N=22$; 
relaxation $\mathrm{N}=25$; fear $\mathrm{N}=25$; sadness $\mathrm{N}=24$ ). These participants reported high intensity of felt moods $($ relaxation $=4.52 ;$ fear $=3.50 ;$ sadness $=3.74 ;$ joy $=4.55)$. Neither gender ratio $\left(\chi^{2}(3)=0.16, p\right.$ $=.984)$ nor age $\left(F(3,92)=0.50, p=.682, \eta_{p}^{2}=.016\right)$ significantly differed between the participants randomly allocated to one of the four mood induction conditions. We additionally explored affective moods reported after the neutral baseline (see Table S3). A chi-square test showed a significant difference in the valence distribution of the rated affective states; $\chi^{2}(2)=82.75, p<.001$, with positive affective states being over-represented (77.1\% participants; $p<.001)$ while neutral $(12.5 \%$; $p<.001)$ or negative $(10.4 \% ; p<.001)$ affective states being under-represented.

\section{Statistical analyses}

We compared hue, lightness, and chroma measured on the CIE LCh system (see Conversion of colour parameters) of the mood induction colours separately to test how colour parameters differed between the different mood induction conditions (joy, relaxation, fear, and sadness). In addition, we compared colour selections following neutral (baseline) mood induction and specific mood induction.

Effects of mood on hue were tested using Watson's two samples test, bootstrapping and chi-square tests. The Watson's two samples non-parametric test was applied to continuous circular hue data testing whether hue choices for each induced affective state condition came from the same distribution ${ }^{71}$. We implemented six tests to compare hue distributions between all possible mood induction combinations (joy-relaxation, joy-fear, joy-sadness, relaxation-fear, relaxation-sadness, and fear-sadness). We excluded achromatic choices as they have no clearly defined hue. We estimated $\mathrm{p}$-values by generating 100,000 random samples ${ }^{72}$, adjusted for multiple comparisons using the False Discovery Rate (FDR) test ${ }^{73}$. The Watson's two samples test was implemented with the R package circular ${ }^{74}$. 
We further used bootstrapping and chi-square tests on categorical hue data (see Hue categorisation) to assess where the differences (if any) between hue distributions came from. Bootstrapping estimated hue differences within each induced mood condition. This method was used due to low number of responses in each hue category for each induced mood condition. We randomly drew 100,000 samples with replacement from the initial hue distribution and compared the proportions of chosen hues between each possible pair of hues (i.e., 36 pairs) to test if certain hues were more often chosen than others for a particular induced affective state. On these bootstrapped samples, we determined the distribution of the differences in choice proportions between all possible hue pairs ( $p_{i}-p_{j}$, i.e., 36 pairs in total) and calculated confidence intervals for each hue pair difference, using a correction for multiple comparisons (alpha/( $\left.\left.\mathrm{k}^{*}(\mathrm{k}-1)\right)\right)$. Alpha corresponded to the threshold of significance (0.050) and k corresponded to the number of possible hue categories (here $k=9$ ). We applied the chi-square tests to compare hue choices as well as choices of warm vs. cool hues across four induced mood conditions. In the cases where expected frequencies in any of the cells fell below 5, Monte Carlo simulation of p-values (based on 2,000 iterations) was used for the chi-square tests. We used standardised residuals to interpret the source of significant differences in the chi-square tests.

Effects of mood on lightness and chroma were tested with independent samples ANOVA tests, with affective state (between-subjects with four levels: joy, relaxation, fear, and sadness) as an independent variable and lightness or chroma as a dependent variable. All post-hoc multiple comparisons were corrected with FDR test ${ }^{73}$. Analyses were performed and graphs created with the $\mathrm{R}^{75}$ and SPSS $22^{76}$ statistical software programs. The alpha level was set at $p=.050$.

\section{Results}

The chosen colours for each induced affective state are displayed in Fig 3 (A.1-A.4).

[Insert Fig 3 around here] 
Watson's two samples tests showed a significant difference between hue distributions of joy and relaxation $\left(U^{2}=.276, p=.011\right)$, joy and fear $\left(U^{2}=.386, p=.002\right)$, joy and sadness $\left(U^{2}=.452, p<\right.$ $.001)$, and relaxation and sadness $\left(U^{2}=.355, p=.002\right)$. There was no significant difference between hue distributions of relaxation and fear $\left(U^{2}=.185, p=.062\right)$ and fear and sadness $\left(U^{2}=.148, p=\right.$ .110). Further, we compared the hue categories of participants' colour choices within affective state conditions by using bootstrapping to establish which hues were most often chosen for joy, relaxation, fear, and sadness (Fig 3, B.1-B.4; see Method section for more details). Yellow was the most often chosen hue for induced joy as compared to any other hue, followed by red, orange, and purple. Other hues (i.e., yellow-green, green, green-blue, blue, and achromatic) were almost never matched to joy (Fig 3, B.1). When looking at relaxation, fear, or sadness, there was no specific hue that would be more often chosen than any other hue associated to these affective states (Fig 3, B.2B.4; Table 2).

[Insert Table 2 around here]

We then used chi-square tests to compare hues between mood conditions. The chi-square test showed an overall significant difference between the hues chosen for different induced moods; $\chi^{2}=$ 78.34, $p<.001$. Yellow hue was more frequently chosen for induced joy (Fig 13, B.1; $p<.001$ ), while yellow-green was more frequently chosen for induced relaxation (Fig 3, B.2; $p<.050$ ) than other affective state. Achromatic colours were more frequently matched to induced sadness (Fig 3, B.4; $p$ $<.010$ ) and less frequently matched to induced relaxation than any other affective state (Fig 3, B.2; $p$ $<.050$ ). No hue was chosen at a different frequency for induced fear (Fig 3, B.3; all ps > .050). No other hue comparisons were significant. A chi-square test comparing warm versus cool hue choices between mood induction conditions was also significant; $\chi^{2}=9.05, p=.025$. Standardised residuals 
indicated that the choice of cool hues was significantly underrepresented in the joy condition $(p<$ .050). No other warm-cool comparisons were significant (Table 3).

[Insert Table 3 around here]

\section{Lightness}

The analysis of variance (ANOVA) showed a significant main effect of affective state; $F(3,92)=29.79$, $p<0.001, \eta_{p}^{2}=0.493$. Post-hoc comparisons showed that colours matched to induced joy were significantly lighter than colours matched to induced fear or sadness but not to relaxation. Colours matched to induced relaxation were significantly lighter than to sadness or fear. There was no further difference in lightness between colours matched to induced sadness and fear (see Fig 3, C.1).

\section{Chroma}

The analogous ANOVA on chroma showed a significant effect of affective state; $F(3,92)=41.00, p<$ $.001, \eta_{p}^{2}=.572$. Post-hoc comparisons indicated that colours matched to joy were significantly more chromatic than to relaxation, fear, or sadness. Colours matched to relaxation were significantly more chromatic than to fear or sadness. Colours matched to fear were significantly more chromatic than to sadness. To sum up, colours matched to joy were the most chromatic and colours matched to sadness were the least chromatic (see Fig 3, C.2).

\section{Baseline colour}

Overall, baseline colour choices originated predominantly from the green-blue hue range $\left(\chi^{2}(8)=\right.$ 73.69, $p<.001$; see Fig 4, A-B); and were more likely to come from cool $(n=51)$ than warm $(n=22)$ hue ranges, $\chi^{2}=11.52, p<.001$. We further tested how hue, lightness, and chroma of the baseline colours differed from hue, lightness, and chroma of the post-mood induction colours. For hue, separate Stuart-Maxwell chi-square tests indicated that frequencies differed between baseline 
colours and, respectively, induced joy $\left(\chi^{2}=16.70, p<.001\right)$, relaxation $\left(\chi^{2}=22.2, p<.001\right)$, fear $\left(\chi^{2}=\right.$ $16.2, p<.001)$, and sadness $\left(\chi^{2}=9.94, p=.002\right)$. Hues matched to joy $(p<0.050)$ as well as sadness $(p<0.050)$ came less often from the green-blue hue range than hues matched to baseline mood (compare Fig 3, B.1-B.4 and Fig 4, B). Watson's two sample tests showed a significant difference between hue distributions of baseline colours and induced joy $\left(U^{2}=.359, p=.004\right)$ as well as induced sadness $\left(U^{2}=.255, p=.021\right)$, but not induced relaxation $\left(U^{2}=.107, p=.250\right)$ or induced fear $\left(U^{2}=.113, p=.250\right)$.

\section{[Insert Fig 4 around here]}

A 2 × 4 ANOVA on lightness values with time as within-subject measure (baseline \& post mood induction) and type of mood induction as between-subjects measure (joy, relaxation, fear, or sadness) showed significant main effects of time $\left(F(1,92)=37.68, p<.001, \eta_{p}{ }^{2}=.291\right)$ and type of mood induction $\left(F(3,92)=14.72, p<.001, \eta_{p}{ }^{2}=.324\right)$, as well as a significant interaction between the two $\left(F(3,92)=23.48, p<.001, \eta_{p}^{2}=.434\right)$. Post-hoc comparisons showed that colours matched to baseline mood were lighter than colours matched to fear or sadness, but not relaxation or joy (see Fig 4, C).

The analogous $2 \times 4$ ANOVA on chroma values showed no main effect of time $(F(1,92)=1.38, p=$ $\left..243, \eta_{p}^{2}=.015\right)$, a significant main effect of mood induction $\left(F(3,92)=17.05, p<.001, \eta_{p}^{2}=.357\right)$, and a significant interaction between the two $\left(F(3,92)=24.44, p<.001, \eta_{p}{ }^{2}=.443\right)$. Post-hoc comparisons showed that the baseline colours were i) less chromatic than colours matched to induced joy, and ii) more chromatic than colours matched to induced sadness, while iii) there were no differences when comparing baseline colours with colours matched to induced relaxation or fear (see Fig 4, D). 


\section{Discussion}

We experimentally manipulated participants' mood to test for systematic relationships between experienced moods and colours. Participants indicated their current mood and chose colours from an unrestricted sample of colours that were the most representative of their current mood at baseline (neutral mental imagery ${ }^{57}$ ) and subsequent to an actual mood induction. We used music and mental imagery via short stories to induce joy, relaxation, fear, or sadness in a between-subject design. As in previous studies ${ }^{39-41,50}$, the mood induction technique was successful, and a large proportion of the participants reported feeling the induced mood. Before discussing results in detail below, we highlight that all three colour dimensions (hue, lightness, and chroma) contributed to explaining the match between mood and colour, which was systematic. While yellow was more often matched to experienced joy and yellow-green to experienced relaxation than any other experienced affective state, other popular claims, such as blue representing experienced relaxation or sadness, did not hold. Lighter and more chromatic colours were more often matched to joy and relaxation than to sadness and fear, with joy representations being the most chromatic and sadness representations being the least chromatic of all. Hence, colour is a reliable yet relatively coarse (compared to popular assumptions) indicator of one's current mood.

Overall, colour choices differed between induced moods. Participants were most congruent in frequently matching yellow hue to induced joy and never matching yellow-green, green, green-blue, or achromatic hues to induced joy. Overall, cool hues were almost never matched to induced joy. The yellow-joy link was previously observed using a varied array of emotion assessment techniques: affective words ${ }^{19}$, affective drawings ${ }^{77}$, affective music ${ }^{46,48}$, and whole body expressions of emotion

22. Yellow also mainly represented self-evaluated mood of participants within a general population ${ }^{11}$. This strong bias to choose yellow for joy might originate from yellow symbolizing summer, good weather, sunshine, warmth and light ${ }^{78}$ - all symbols are certainly very positive for most people. Although not as often as yellow, other warm hues (red and orange) were also matched to induced 
joy. These hues may to some extent carry similar connotations. One should note, however, that the positive association with yellow only stands when yellow is bright and chromatic (i.e., the focal yellow). When yellow is darker and more greyish, it is perceived as the least pleasant colour ${ }^{16,60}$. In the current analyses too we reported colours matched to joy being the most chromatic of all induced moods or baseline mood and lighter than colours matched to negative induced moods (sadness and fear). We conclude that the association between joy and relatively light chromatic yellow seems to be a stable phenomenon, observable irrespective of the affect assessment procedure.

Contrary to expectations, we found little evidence for an association between blue and induced relaxation ${ }^{23,79}$ and even less so for induced sadness ${ }^{46,48}$. While blue was the most frequent hue choice matched to relaxation, blue choice was not more common than any other hue, meaning that the difference with other hue choices was too low to be statistically reliable (i.e., may have occurred due to chance). Cool hues were also not more likely to be associated with relaxation than warm hues. In contrast, compared to other induced moods, green-yellow hue choices were specifically, yet infrequently, matched to the experience of relaxation, as this hue was more often matched to experience of relaxation than any other mood. For sadness, another low arousing mood, most matched colours were achromatic. Our analyses of lightness and chroma further indicated that colours matched to sadness were darker than those matched to positive moods (joy and relaxation) and the least chromatic of all the induced moods. These findings resemble previously reported observations that clinically depressed or anxious participants match their mood to shades of grey $11,13,15$. Thus, it seems that dark achromatic colours can also indicate a negative mood, such as sadness or fear, in a general, that is non-clinical, population.

\section{Practical implications}


Colour tests have been used commercially and clinically to infer about other's personality ${ }^{3}$ or behavioural tendencies ${ }^{4}$ without little empirical support of whether colour choices can indicate one's internal affective states (e.g., mood). The results of the current study lend support to some of these popular notions ${ }^{1-4}$. Here, we demonstrated that colour matches are indicative of one's current mood, when the latter had been experimentally manipulated. In cases when indirect assessment of mood may be preferred (e.g., in clinical populations ${ }^{80}$, children and adolescent populations ${ }^{81}$ ), colour matches to one's mood could be used as an alternative or an additional form of assessment. One should note, however, that colour associations do not seem very specific. We found that two negative moods (i.e., sadness and fear) were matched to dark achromatic colours and two positive moods (i.e., joy and relaxation) were matched to lighter and more chromatic colours. Thus, in order to use the current results for specific applications, more affect-specific outcomes must be obtained. Given the current state of evidence-based knowledge, practitioners interested in using colour matching paradigms to infer about others' internal affective states in applied settings should be advised to combine colour matches with other assessment techniques (other behavioural or verbal indices).

\section{Challenges and future directions}

The current study was limited in understanding why particular colours were chosen for specific induced moods. While the study was not designed to answer such a question, one could speculate on several potential reasons. It is possible that the short stories of the mood induction procedure evoked mental imagery, which contributed to the reported colour associations. For example, imagery of an ocean could explain blue choices in the baseline condition. Imagery of a fireplace, burning candle and sunset could explain choices of warm colours for relaxation. While this hypothesis is suitable to explain colour choices in some cases, it is less applicable in other cases. For example, soft snow was mentioned in the relaxation condition, but no one chose white (although one light blue choice could be related to this imagery). Rain and winter were mentioned in the joy 
condition but almost no one chose cool colours. We acknowledge the possibility that different short stories could lead to different colour choices. It is also possible that colour-mood choices were mediated by the synaesthetic-like experiences evoked by music. While synaesthesia (i.e., matching two unrelated modalities like colour and sound) is a rather infrequent condition ${ }^{82}$, people without synaesthesia can hold systematic colour-music associations too, yet less strong ${ }^{83}$. Colour matches to joyful mood included a lot of yellow colours, and so did colour matches to "joyful" music in previous studies ${ }^{46,47}$. Alternatively, participants could be labelling their felt mood and associating emotion concepts with colours. All these affective associations with colour could have been shaped by human experience with colour in their environment (a similar hypothesis was proposed to explain colour preferences ${ }^{84}$ ) or by one's culture and native language ${ }^{24}$. Future investigations are needed to shed light on these questions

\section{Conclusions}

The current study demonstrated that colour matches are indicative of one's current affective state, when the latter is experimentally manipulated. We demonstrated that colour matches to felt affective states were systematic and in part resembled colour associations to conceptually appraised affective states (e.g., black and sadness, yellow and joy). These results lend some support to the popular notion that colour can be used to infer about others' internal affective states. Importantly, however, colour associations were not necessarily very specific. Both negative affective states (i.e., sadness and fear) were matched to dark achromatic colours while both positive affective states (i.e., joy and relaxation) were matched to lighter and more chromatic colours. Researchers or practitioners interested in person profiling should thus be advised to combine colour matches with perhaps other assessment techniques (other behavioural or verbal indices) to improve specificity on inferences about others' affective states. Future studies are needed to assess colour matches to other affective states and identify the degree of specificity of colour-mood matches. They should 
Jonauskaite et al. (2019)

also tackle the underlying reasons behind affective associations with colour. Taken together, among many other ways, colour opens a window to take a peek at other's internal affective world. 


\section{References}

1. Your Personality Color. Your personality color. Empower. by colour 2017. Available at: http://www.empower-yourself-with-color-psychology.com/personality-color.html. Accessed January 19, 2018.

2. What's Your Personality Color. What's your personality color? Psychologia 2018. Available at: http://psychologia.co/personality-color/. Accessed January 19, 2018.

3. Hartman T. Color Code. Color Code International; 1987.

4. Lüscher M. The Lüscher Color Test. New York: Random House; 1969.

5. French CA, Alexander AB. The Lüscher color test: An investigation of validity and underlying assumptions. J. Pers. Assess. 1972;36(4):361-365. doi:10.1080/00223891.1972.10119772.

6. Kertzman S, Spivak B, Ben-Nahum Z, et al. Variability of color choice in the Lüscher color test-Sex differences. Percept. Mot. Skills 2003;97(5):647. doi:10.2466/PMS.97.5.647-656.

7. Holmes CB, Wurtz PJ, Waln RF, Dungan DS, Joseph CA. Relationship between the Luscher Color Test and the MMPI. J. Clin. Psychol. 1984;40(1):126-8. Available at: http://www.ncbi.nlm.nih.gov/pubmed/6746918. Accessed January 19, 2018.

8. Basra R, Cortes E, Khullar V, Kelleher C. Do colour and personality influence treatment seeking behaviour in women with lower urinary tract symptoms? A prospective study using the short Lüscher colour test. J. Obstet. Gynaecol. 2009;29(5):407-11. doi:10.1080/01443610902937399.

9. Savio F, Zanardo V. Unconscious dynamics in twin pregnancy emerging from the Lüscher color test. J. Matern. Neonatal Med. 2015;28(2):199-203. doi:10.3109/14767058.2014.907263.

10. Zanardo V, Gabrieli C, Volpe F, Savio F, Straface G, Soldera G. Postpartum unconscious dynamics emerging from the Lüscher color test in Ethiopian women. J. Matern. Neonatal Med. 2017;30(12):1446-1449. doi:10.1080/14767058.2016.1219985. 
11. Carruthers HR, Morris J, Tarrier N, Whorwell PJ. The Manchester Color Wheel: development of a novel way of identifying color choice and its validation in healthy, anxious and depressed individuals. BMC Med. Res. Methodol. 2010;10:12. doi:10.1186/1471-2288-10-12.

12. Carruthers HR, Morris J, Tarrier N, Whorwell PJ. Mood color choice helps to predict response to hypnotherapy in patients with irritable bowel syndrome. BMC Complement. Altern. Med. 2010;10(1):75. doi:10.1186/1472-6882-10-75.

13. Carruthers HR, Magee L, Osborne S, Hall LK, Whorwell PJ. The Manchester Color Wheel: validation in secondary school pupils. BMC Med. Res. Methodol. 2012;12(1):136. doi:10.1186/1471-2288-12-136.

14. Rosenbloom T. Color preferences of high and low sensation seekers. Creat. Res. J. 2006;18(2):229-235. doi:10.1207/s15326934crj1802.

15. Nolan RF, Dai Y, Stanley PD. An investigation of the relationship between color choice and depression measured by the Beck Depression Inventory. Percept. Mot. Skills 1995;81:11951200. doi:10.2466/pms.1995.81.3f.1195.

16. Valdez P, Mehrabian A. Effects of color on emotions. J. Exp. Psychol. Gen. 1994;123(4):394409. doi:10.1037/0096-3445.123.4.394.

17. Ou L-C, Luo MR, Woodcock A, Wright A. A study of colour emotion and colour preference. Part I: Colour emotions for single colours. Color Res. Appl. 2004;29(3):232-240. doi:10.1002/col.20010.

18. Soriano C, Valenzuela J. Emotion and colour across languages: implicit associations in Spanish colour terms. Soc. Sci. Inf. 2009;48(3):421-445. doi:10.1177/0539018409106199.

19. Sutton TM, Altarriba J. Color associations to emotion and emotion-laden words: A collection of norms for stimulus construction and selection. Behav. Res. Methods 2016;48(2):686-728. doi:10.3758/s13428-015-0598-8.

20. Adams FM, Osgood CE. A cross-cultural study of the affective meanings of color. J. Cross. Cult. Psychol. 1973;4(2):135-157. doi:10.1177/002202217300400201. 
21. Specker $E$, Leder $H$, Rosenberg $R$, et al. The universal and automatic association between brightness and positivity. Acta Psychol. (Amst). 2018;186:47-53. doi:10.1016/j.actpsy.2018.04.007.

22. Dael N, Perseguers M-N, Marchand C, Antonietti J-P, Mohr C. Put on that colour, it fits your emotion: Colour appropriateness as a function of expressed emotion. Q. J. Exp. Psychol. (Hove). 2015;218(October):1-12. doi:10.1080/17470218.2015.1090462.

23. Simmons DR. Colour and emotion. In: Biggam, CP, Hough CA, Kay CJ, Simmons DR, eds. New Directions in Colour Studies. Amsterdam/ Philadelphia: John Benjamins Publishing Company; 2011:395-413. doi:10.1075/z.167.44sim.

24. Hupka RB, Zaleski Z, Otto J, Reidl L, Tarabrina N V. The colours of anger, envy, fear, and jealousy. J. Cross. Cult. Psychol. 1997;28(2):156-171.

25. Dan-Glauser ES, Scherer KR. The Geneva affective picture database (GAPED): a new 730picture database focusing on valence and normative significance. Behav. Res. Methods 2011;43(2):468-477. doi:10.3758/s13428-011-0064-1.

26. Schaefer A, Nils F, Sanchez X, Philippot P. Assessing the effectiveness of a large database of emotion-eliciting films: A new tool for emotion researchers. Cogn. Emot. 2010;24(7):11531172. doi:10.1080/02699930903274322.

27. Duclos SE, Laird JD. The deliberate control of emotional experience through control of expressions. Cogn. Emot. 2001;15(1):27-56. doi:10.1080/02699930126057.

28. Eich E, Ng JTW, Macaulay D, Percy AD, Grebneva I. Combining music with thought to change mood. In: Allen JJB, Coan JA, eds. The Handbook of Emotion Elicitation and Assessment. New York, NY: Oxford University Press; 2007:124-136.

29. Västfjäll D. Emotion induction through music: A review of the musical mood induction procedure. Music. Sci. 2001;5(1_suppl):173-211. doi:10.1177/10298649020050S107.

30. Niedenthal PM, Halberstadt JB, Setterlund MB. Being happy and seeing "happy": Emotional state mediates visual word recognition. Cogn. Emot. 1997;11(4):403-432. 
doi:10.1080/026999397379863.

31. Juslin PN, Laukka P. Expression, perception, and induction of musical emotions: A review and a questionnaire study of everyday listening. J. New Music Res. 2004;33(3):217-238. doi:10.1080/0929821042000317813.

32. Cespedes-Guevara J, Eerola T. Music communicates affects, not basic emotions - A constructionist account of attribution of emotional meanings to music. Front. Psychol. 2018;9(FEB):1-19. doi:10.3389/fpsyg.2018.00215.

33. Eerola T, Peltola HR. Memorable experiences with sad music-reasons, reactions and mechanisms of three types of experiences. PLoS One 2016;11(6). doi:10.1371/journal.pone.0157444.

34. Kawakami A, Furukawa K, Katahira K, Okanoya K. Sad music induces pleasant emotion. Front. Psychol. 2013;4(June):1-15. doi:10.3389/fpsyg.2013.00311.

35. Schubert E. Enjoying sad music: Paradox or parallel processes? Front. Hum. Neurosci. 2016;10:1-8. doi:10.3389/fnhum.2016.00312.

36. Sachs ME, Damasio A, Habibi A. The pleasures of sad music: a systematic review. Front. Hum. Neurosci. 2015;9(July):1-12. doi:10.3389/fnhum.2015.00404.

37. Vuoskoski JK, Eerola T. The pleasure evoked by sad music is mediated by feelings of being moved. Front. Psychol. 2017;8(MAR):1-11. doi:10.3389/fpsyg.2017.00439.

38. Gilet AL. Procédures d'induction d'humeurs en laboratoire : Une revue critique [Mood induction procedures: A critical review]. Encephale 2008;34(3):233-239. doi:10.1016/j.encep.2006.08.003.

39. Jallais C, Gilet A-L. Inducing changes in arousal and valence: Comparison of two mood induction procedures. Behav. Res. Methods 2010;42(1):318-325. doi:10.3758/BRM.42.1.318.

40. Zhang X, Yu HW, Barrett LF. How does this make you feel? A comparison of four affect induction procedures. Front. Psychol. 2014;5(JUL):1-10. doi:10.3389/fpsyg.2014.00689.

41. Mayer JD, Allen JP, Beauregard K. Mood inductions for four specific moods: A procedure 
employing guided imagery vignettes with music. J. Ment. Imag. 1995;19(1-2):133-150.

42. Geaney JT, Treadway MT, Smillie LD. Trait anticipatory pleasure predicts effort expenditure for reward. PLoS One 2015;10(6):e0131357. doi:10.1371/journal.pone.0131357.

43. Rigoni D, Demanet J, Sartori G. Happiness in action: the impact of positive affect on the time of the conscious intention to act. Front. Psychol. 2015;6:1-9. doi:10.3389/fpsyg.2015.01307.

44. Propper RE, Barr TD, Brunyé TT. Lateralized differences in tympanic membrane temperature, but not induced mood, are related to episodic memory. Brain Cogn. 2015;94:52-59. doi:10.1016/j.bandc.2015.01.005.

45. Corson Y. Émotions et propagation de l'activation en mémoire sémantique [Emotions and propagation of activation in semantic memory]. Can. J. Exp. Psychol. 2006;60(2):127-147. doi:10.1037/cjep2006013.

46. Palmer SE, Schloss KB, Xu Z, Prado-León LR. Music-color associations are mediated by emotion. Proc. Natl. Acad. Sci. U. S. A. 2013;110(22):8836-41. doi:10.1073/pnas.1212562110.

47. Palmer SE, Langlois TA, Schloss KB. Music-to-color associations of single-line piano melodies in non-synesthetes. Multisens. Res. 2015;29(1-3):157-193. doi:10.1163/22134808-00002486.

48. Lindborg P, Friberg AK. Colour association with music is mediated by emotion: Evidence from an experiment using a CIE Lab interface and interviews. PLoS One 2015;10(12):e0144013. doi:10.1371/journal.pone.0144013.

49. Bhattacharya J, Lindsen JP. Music for a brighter world: Brightness judgment bias by musical emotion. PLoS One 2016;11(2):1-11. doi:10.1371/journal.pone.0148959.

50. Corson Y, Verrier N. Emotions and false memories. Psychol. Sci. 2007;18(3):208-211. doi:10.1111/j.1467-9280.2007.01874.x.

51. Scherer KR. What are emotions? And how can they be measured? Soc. Sci. Inf. 2005;44(4):695-729. doi:10.1177/0539018405058216.

52. Hunt RWG, Pointer MR. Colour order systems. In: Measuring Colour. Fourth edi. John Wiley \& Sons, Ltd.; 2011:155-195. 
53. Ishihara S. Album-Test Pour La Recherche Des Dyschromatopsies Congenitales, 38 Plates Edn. [Ishihara's Test for Colour Deficiency: 38 Plates Edition]. Tokyo: Kanehara (Original work published 1917); 1993.

54. Simmons JP, Nelson LD, Simonsohn U. False-positive psychology: Undisclosed flexibility in data collection and analysis allows presenting anything as significant. Psychol. Sci. 2011;22(11):1359-1366. doi:10.1177/0956797611417632.

55. Faul F, Erdfelder E, Lang A-G, Buchner A. G*Power: A flexible statistical power analysis program for the social, behavioral, and biomedical sciences. Behav. Res. Methods 2007;39(2):175-191. doi:10.3758/BF03193146.

56. Velten E. A laboratory task for induction of mood states. Behav. Res. Ther. 1968;6(4):473-482. doi:10.1016/0005-7967(68)90028-4.

57. Vohs KD, Schooler JW. The value of believing in free will: Encouraging a belief in determinism increases cheating. Psychol. Sci. 2008;19(1):49-54. doi:10.1111/j.1467-9280.2008.02045.x.

58. Gerrards-Hesse A, Spies K, Hesse FW. Experimental inductions of emotional states and their effectiveness: A review. Br. J. Psychol. 1994;85(1):55-78. doi:10.1111/j.20448295.1994.tb02508.x.

59. Westermann R, Stahl G, Hesse FW. Relative effectiveness and validity of mood induction procedures: A meta-analysis. Eur. J. Soc. Psychol. 1996;26(January 1995):557-580. doi:doi.org/10.1002/(SICI)1099-0992(199607)26:4<557::AID-EJSP769>3.0.CO;2-4.

60. Jonauskaite D, Mohr C, Antonietti J-P, et al. Most and least preferred colours differ according to object context: New insights from an unrestricted colour range. PLoS One 2016;11(3):1-22. doi:10.1371/journal.pone.0152194.

61. Jonauskaite D, Dael N, Chèvre L, et al. Pink for girls, red for boys, and blue for both genders: Colour preferences in children and adults. Sex Roles in press. doi:10.1007/s11199-018-0955-z.

62. Scherer KR, Shuman V, Fontaine JRJ, Soriano C. The GRID meets the Wheel: Assessing emotional feeling via self-report. In: Fontaine JRJ, Scherer KR, Soriano C, eds. Components of 
Emotional Meaning: A Sourcebook. Oxford: Oxford University Press; 2013:1-34.

63. Fontaine JJR, Scherer KR, Soriano C. Components of Emotional Meaning. A Sourcebook. New York: Oxford University Press; 2013. doi:10.1093/acprof:oso/9780199592746.001.0001.

64. Lieberman MD, Inagaki TK, Tabibnia G, Crockett MJ. Subjective responses to emotional stimuli during labeling, reappraisal, and distraction. Emotion 2011;11(3):468-480. doi:10.1037/a0023503.

65. Lindbloom B. Useful colour equations. 2017. Available at: http://www.brucelindbloom.com/. Accessed September 9, 2017.

66. Fortmann-Roe S. Effects of hue, saturation, and brightness on color preference in social networks: Gender-based color preference on the social networking site Twitter. Color Res. Appl. 2011;38(3):196-202. doi:10.1002/col.20734.

67. Parraga CA, Akbarinia A. NICE: A computational solution to close the gap from colour perception to colour categorization. PLoS One 2016;11(3). doi:10.1371/journal.pone.0149538.

68. Ou L-C. Color emotion and color harmony. In: Elliot AJ, Fairchild MD, Franklin A, eds. Handbook of Color Psychology. Cambridge: Cambridge University Press; 2015:401-418. doi:10.1017/СВ09781107337930.020.

69. Fontaine JRJ, Scherer KR, Roesch EB, Ellsworth PC. The world of emotions is not twodimensional. Psychol. Sci. 2007;18(12):1050-1057.

70. Trost W, Ethofer T, Zentner M, Vuilleumier P. Mapping aesthetic musical emotions in the brain. Cereb. Cortex 2012;22(12):2769-2783. doi:10.1093/cercor/bhr353.

71. Watson GS. Goodness-of-fit test on a circle. Biometrika 1961;48(1-2):109-114. doi:10.1093/biomet/49.1-2.57.

72. Pewsey A, Neuhäuser M, Ruxton GD. Circular Statistics in R. New York: Oxford University Press; 2013.

73. Benjamini Y, Hochberg Y. Controlling the false discovery rate: A practical and powerful 
approach to multiple testing. J. R. Stat. Soc. Ser. B 1995;57(1):289-300. doi:10.2307/2346101.

74. Agostinelli C, Lund U. R package "circular": Circular statistics (version 0.4-93). 2017. Available at: https://r-forge.r-project.org/projects/circular/.

75. R Core Team. R: A language and environment for statistical computing. R Foundation for Statistical Computing. 2018. Available at: https://www.r-project.org/.

76. IBM Corp. IBM SPSS statistics for Macintosh. 2013.

77. Burkitt E, Sheppard L. Children's colour use to portray themselves and others with happy, sad and mixed emotion. Educ. Psychol. 2014;34(2):231-251. doi:10.1080/01443410.2013.785059.

78. Yu H-C. A Cross-Cultural Analysis of Symbolic Meanings of Color. Chang Gung J. Humanit. Soc. Sci. 2014;7(1):49-74.

79. Al-Ayash A, Kane RT, Smith D, Green-Armytage P. The influence of color on student emotion, heart rate, and performance in learning environments. Color Res. Appl. 2016;41(2):196-205. doi:10.1002/col.21949.

80. Patrick CJ, Bradley MM, Lang PJ. Emotion in the criminal psychopath: Startle reflex modulation. J. Abnorm. Psychol. 1993;102(1):82-92. doi:10.1037/0021-843X.102.1.82.

81. Zeman J, Klimes-Dougan B, Cassano M, Adrian M. Measurement issues in emotion research with children and adolescents. Clin. Psychol. Sci. Pract. 2007;14(4):377-401. doi:10.1111/j.1468-2850.2007.00098.x.

82. Ward J. Synesthesia. Annu. Rev. Psychol. 2013;64(1):49-75. doi:10.1146/annurev-psych113011-143840.

83. Spence C. Crossmodal correspondences: A tutorial review. Attention, Perception, Psychophys. 2011;73(4):971-995. doi:10.3758/s13414-010-0073-7.

84. Palmer SE, Schloss KB. An ecological valence theory of human color preference. Proc. Natl. Acad. Sci. U. S. A. 2010;107(19):8877-82. doi:10.1073/pnas.0906172107. 


\section{Author biographies}

Domicele Jonauskaite is a doctoral student in the Institute of Psychology at the University of Lausanne in Switzerland. Her doctoral position was financially supported by the Swiss National Science Foundation with a personal Doc.CH grant to investigate inter-individual and cross-cultural differences in affective connotations of colour. Previously, she completed BSc degree in Psychology at Royal Holloway, University of London, UK, and MSc degree in Neuroscience at the University of Geneva, Switzerland. Together with Christine Mohr and Nele Dael, they have founded Colour Experience (colourexperience.ch) platform designed to disseminate scientifically validated empirical research on psychological effects of colour.

Betty Althaus was a student assistant in the Institute of Psychology at the University of Lausanne in Switzerland from 2015 to 2016 . There, she worked on various research projects on psychological effects of colour and on emotions. During that time, she also completed her MSc degree in Clinical Psychology and Psychopathology at the University of Lausanne, and wrote the MSc thesis on colour associations with induced affective states. She now works as a research fellow for the Palliative and Supportive Care Service of the Lausanne University Hospital in Switzerland on a positive psychology research with palliative patients.

Nele Dael obtained a PhD in Affective Sciences from the University of Geneva (Switzerland) on the expression and perception of emotion through body movement. She then pursued her post-doctoral studies at the Institute of Psychology, University of Lausanne (Switzerland) where she investigated the impact of colour on cognitive-affective processes. She continues this research as a consultant at Colour Experience (colourexperience.ch, co-founder) in affiliation with the University of Lausanne.

Elise S. Dan-Glauser is a researcher and senior lecturer at the Institute of Psychology, University of Lausanne, Switzerland. She obtained a PhD in Affective Sciences from the University of Geneva, and conducted a post-doctoral training on emotion regulation at Stanford University, CA, USA. Her work 
mainly focuses on emotion emergence and emotion regulation processes. She is particularly interested in how stimuli characteristics lead to emotion emergence, and how individual characteristics relate to emotion regulation strategy use and efficiency.

Christine Mohr is Professor for Cognitive Psychology at the University of Lausanne, Switzerland. She graduated with a Psychology degree from the University of Konstanz, Germany. Subsequently she completed her PhD at the Institute of Psychology at the University of Zürich, Switzerland. After postdoctoral studies in Geneva, Switzerland and Edmonton, Canada, she continued her academic career as a lecturer and later senior lecturer at Bristol University, UK. Now in Lausanne, she focuses on two major research lines: 1) colour psychology with a particular interest in the relationship between colour and affect, and 2) cognitive and affective factors in adult belief and its formation. By today, she authored or co-authored over 100 peer-reviewed research contributions. 


\section{Figures}

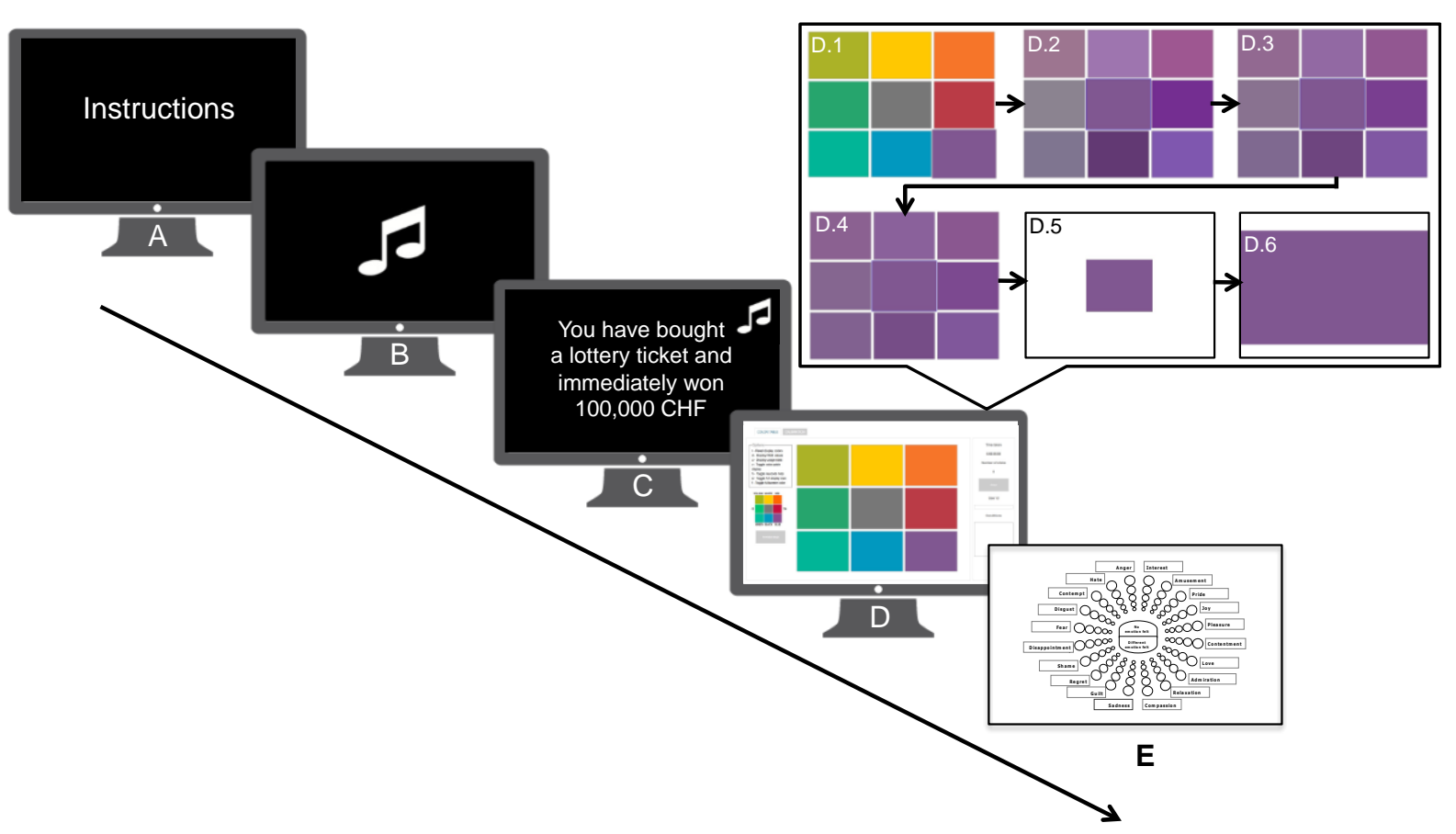

Fig 1. The timeline of the procedure of the study. (A) Instructions for the experiment. (B) Mood induction (part 1) with music for 4 minutes. (C) Mood induction (part 2) with music and short stories for 4 to 4.5 minutes. (D) Colour picker tool used to select colours that match the induced affective state. (D.1) Initial screen. A slightly larger square (here the purple one) shows which colour has been chosen and will be refined further. (D.2) - (D.4) subsequent screens of colour selection. (D.5) Final selection screen. (D.6) Screen with the enlarged selected colour to verify the selection. One should note that it was always possible to return to the previous selection screens and refine the colour selection. This particular example of the colour selection took 4 clicks to make. The colour picker can be accessed via https://www2.unil.ch/onlinepsylab/ColourPicker/html/colourpicker.html. (E). The Geneva Emotion Wheel (GEW) to select the affective state that one was feeling after the mood induction, answered on a paper questionnaire. For a larger version of the GEW, see Fig 2. 


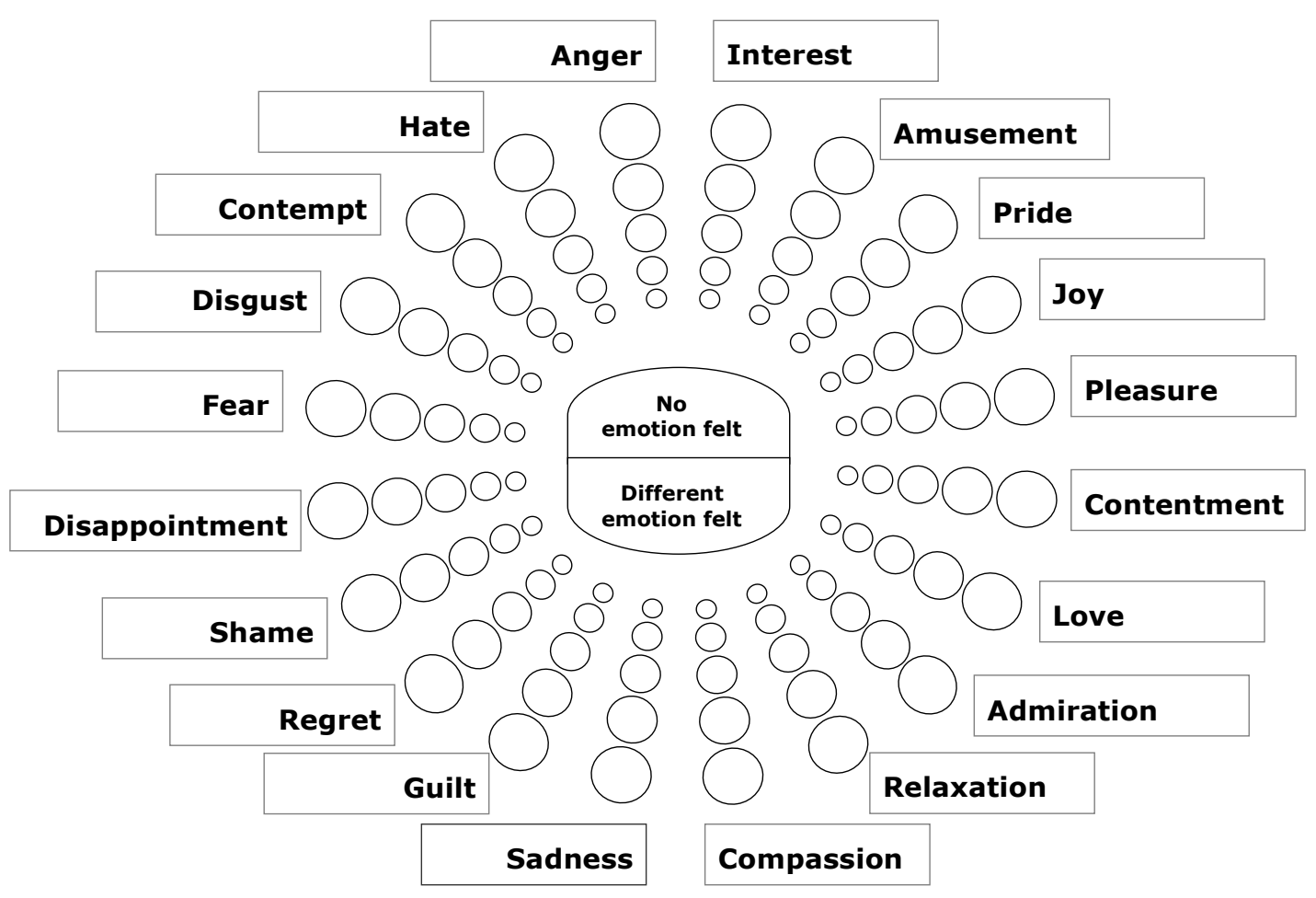

Fig 2. Geneva Emotion Wheel version 3.0 used to assess affective states felt after the mood induction ${ }^{51,62}$. Note that for the purposes of the current study, we exchanged relief with relaxation. 


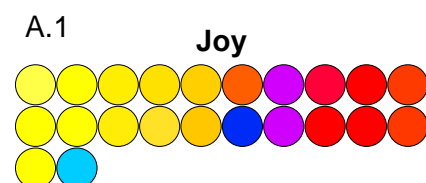

B. 1

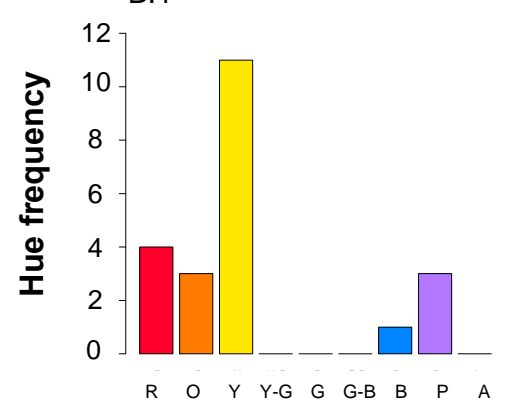

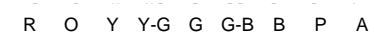
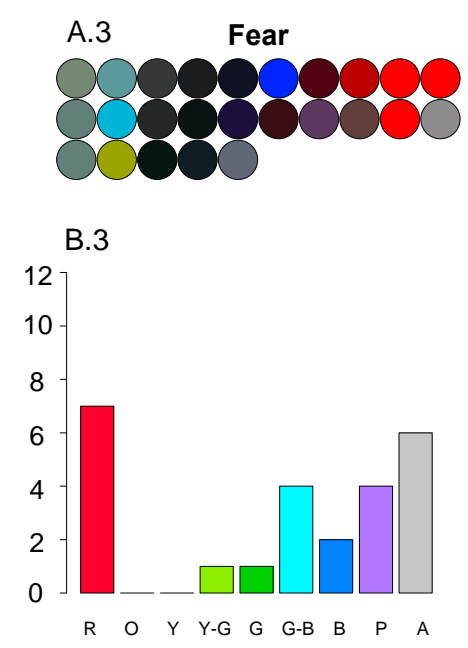

A.2

Relaxation

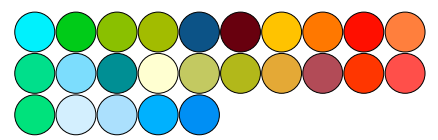

B. 2

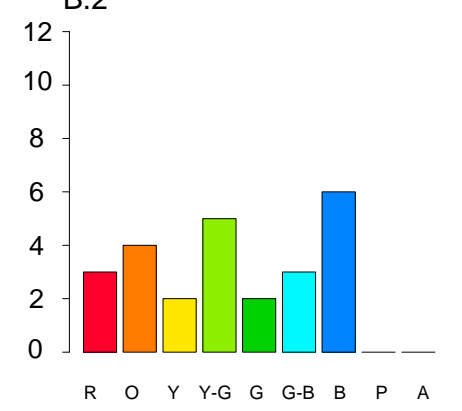

A. 4

Sadness
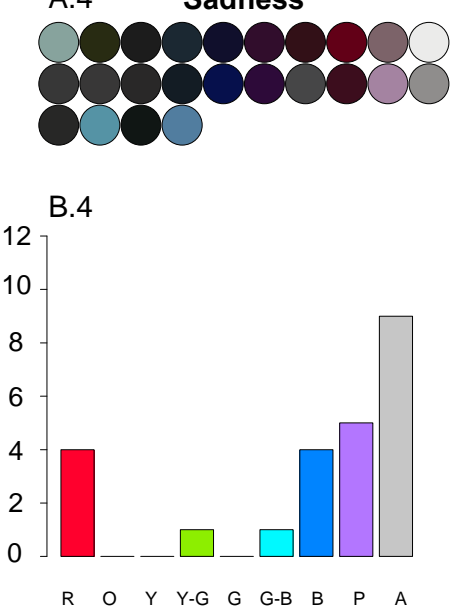

C.1 Lightness

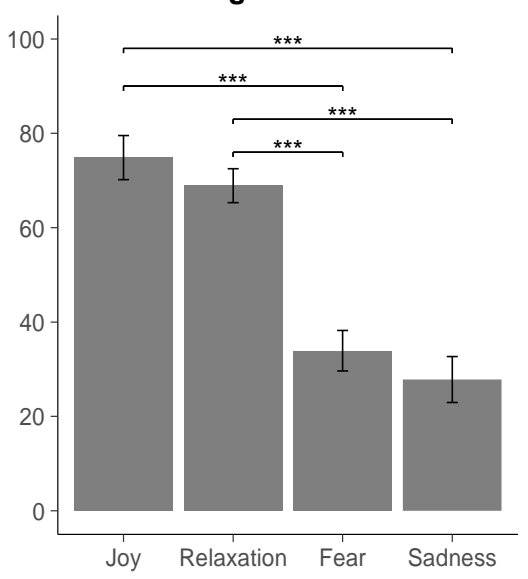

C.2

Chroma

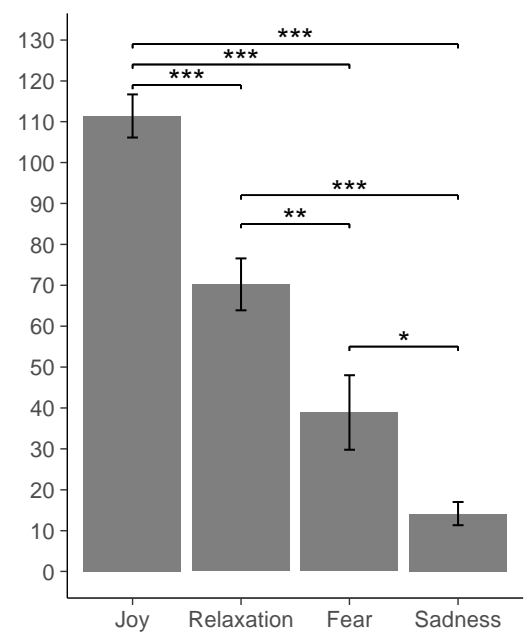

Fig 3. Raw colour selections (A.1-A.4) as well as variation in hue (B.1-B.4), lightness (C.1), and chroma (C.2) between the induced affective states of joy, relaxation, fear, and sadness. Hue codes: $\mathrm{R}=\mathrm{red}, \mathrm{O}$ = orange, $\mathrm{Y}=$ yellow, $\mathrm{Y}-\mathrm{G}=$ yellow-green, $\mathrm{G}=$ green, $\mathrm{G}-\mathrm{B}=$ green-blue, $\mathrm{B}=$ blue, $\mathrm{P}=$ purple, $\mathrm{A}=$ achromatic (i.e., shades of grey from black to white). Error bars indicate one standard error of the mean (SEM). Significance coded as $* p<.050, * * p<.010, * * * p<.001$ 
A

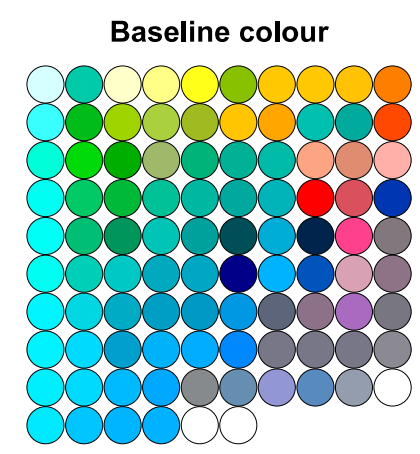

B

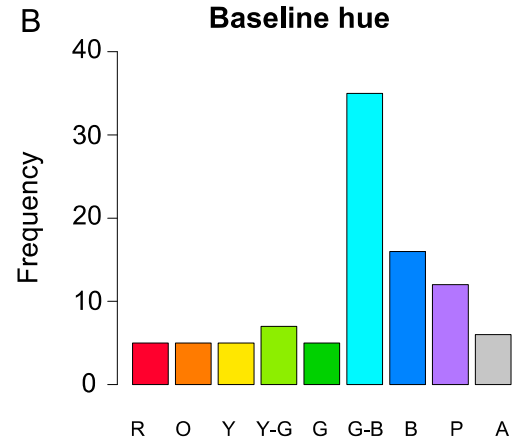

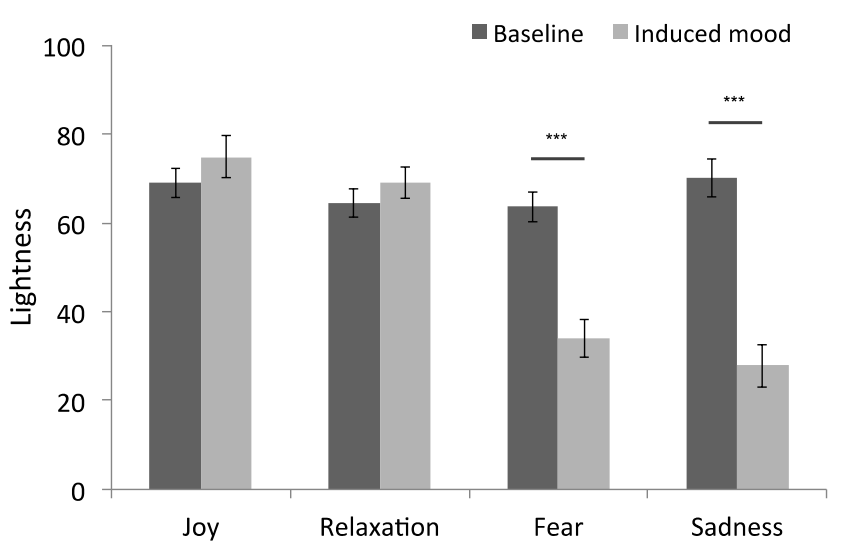

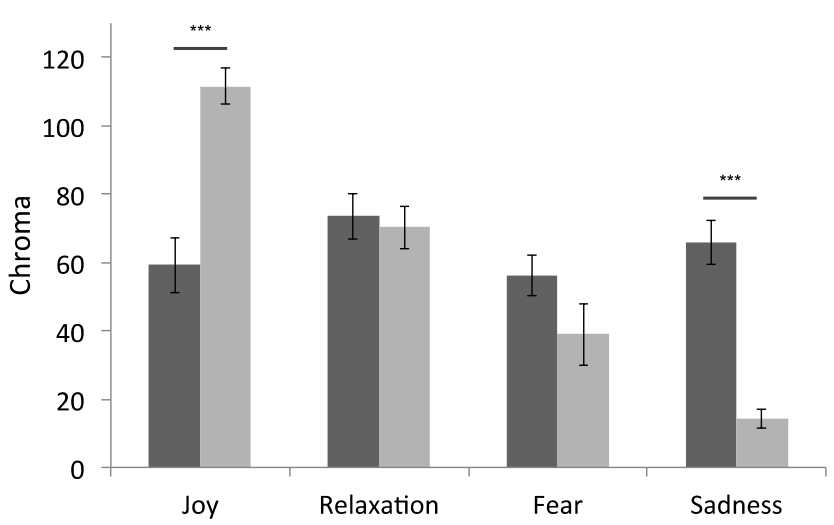

C

D

Fig 4. Raw colour selections $(A)$ and variations in hue (B), lightness (C), and chroma (D) between colours matched to participants' mood prior to mood induction (baseline) and to induced affective states of joy, relaxation, fear, or sadness. Hue codes: $R=$ red, $O=$ orange, $Y=$ yellow, $Y-G=$ yellowgreen, $\mathrm{G}=$ green, $\mathrm{G}-\mathrm{B}=$ green-blue, $\mathrm{B}=$ blue, $\mathrm{P}=$ purple, $\mathrm{A}=$ achromatic (i.e., shades of grey from black to white). Error bars indicate one standard error of the mean (SEM). Significance coded as $* p$ $<.050, * * p<.010, * * * p<.001$ 
Tables

Table 1. Short stories and music used for mood induction, taken from previous studies ${ }^{41,45,50,57}$

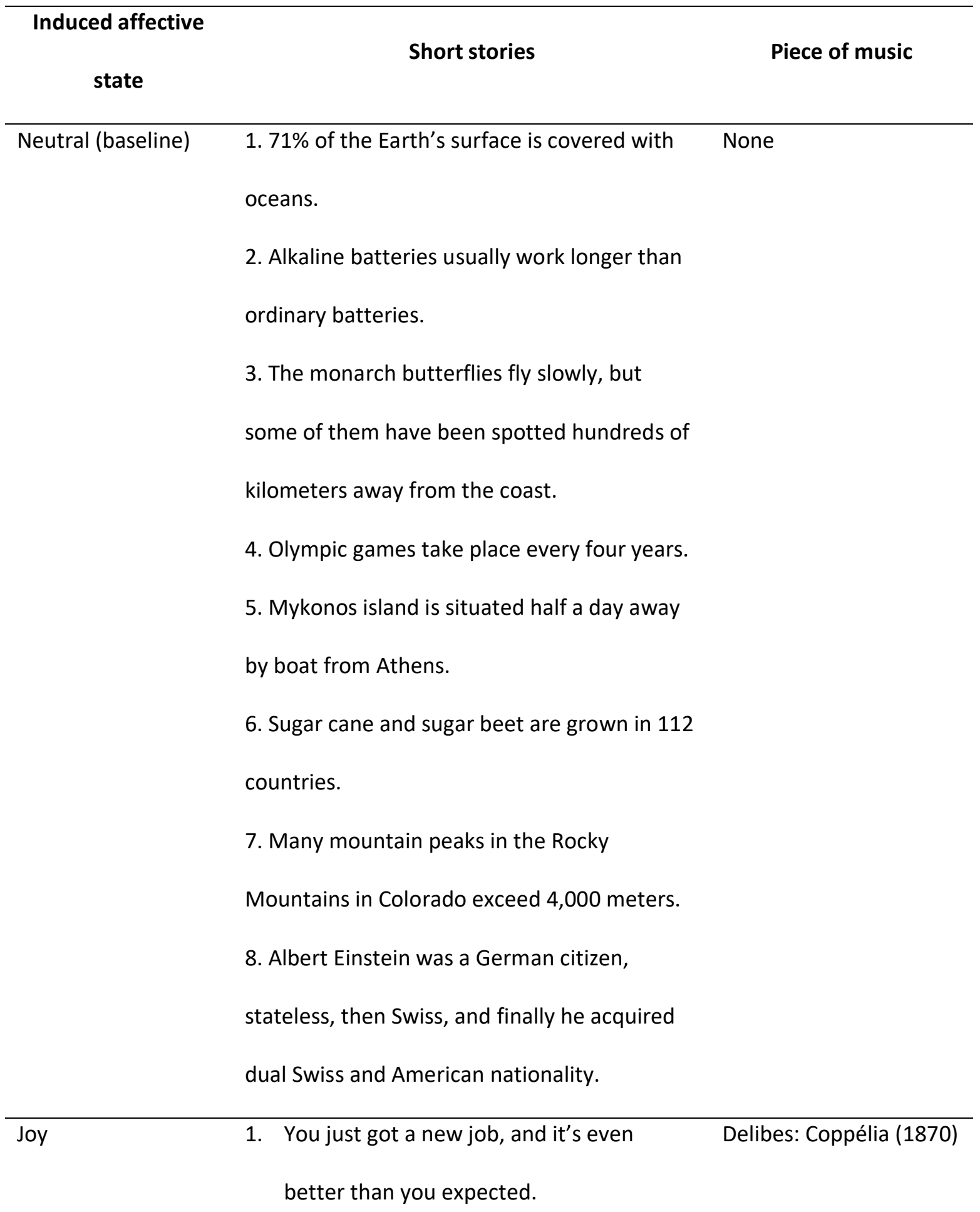

2. You wake up on a Saturday after a number 
of wintry-cold rainy days, and the

temperature is above $15^{\circ} \mathrm{C}$.

3. You buy a lottery ticket and you win

10,000 CHF immediately.

4. You and a friend go to a nice restaurant.

The meal, the conversation, and the

atmosphere are all perfect.

5. You get out of class or work early. It's a beautiful day and you and some friend go for an ice cream.

6. You spend a day in the mountains; the air is clean and sharp, the day sunny, and you take a swim in a beautiful lake.

7. You unexpectedly run into someone you like. You go for coffee and have a great conversation. You discover you think alike, and share many of the same interests.

8. It's your birthday and friends throw you a terrific surprise party.

Garceau \& lachini: novel by a fireplace. 
2. While lying on a deckchair in the garden,

you are enjoying the surrounding nature.

3. You are quietly looking at a burning candle.

4. After a long winter day, you are calmly

taking a hot bath.

5. You are on the beach watching the sun

setting down in the horizon on a gentle and

calm evening.

6. Outside, the rain is falling on the roof top

while you are sitting inside wrapped in a

duvet.

7. You are walking on soft snow which absorbs

all the sounds.

8. You feel good, you are breathing calmly and

you are pleasantly relaxed. man walks in and pulls out a knife. He stares at you without saying what he wants.

2. You are in an overcrowded carriage at the top of a ferris wheel when the mechanism malfunctions and the wheel jams. A thunder storm is developing, and the wheel sways in the wind, its metal creaking.

3. Your car breaks down on a back street in the dangerous part of the city. You start to go 
for help when you see several teenage boys

walking toward you in a threatening way.

4. You are driving down an unfamiliar road on

a stormy night when your car skids out of

control.

5. You are driving down the road when a

tractor trailer going in the opposite direction

crosses over into your lane.

6. You are in your bedroom late at night when

you hear someone enter your apartment. No

one else you know has a key.

7. You are swimming in a dark lake and

something big, slimy, and prickly brushes

against your leg.

8. You are having a nightmare about someone

chasing you and you fall into a bottomless pit.

You start scream in your sleep.

Sadness

1. You read in the newspaper a teacher you

Chopin: Prelude Opus

used to house-sit for recently past away.

28, no 6 (1939)

2. You are told by a young relative that she

has cancer and only six months to live.

3. You have been dating someone and you

thought it looked quite promising, when the

person calls you up and tells you he/she

doesn't want to see you any more. 
4. A pet you were really fond of has died.

5. Your best friend just got married and is

moving far away from you.

6. No one remembers your birthday.

7. A relative of yours, with whom you've

shared a close relationship, has been

diagnosed as having cancer and has only a

short time to live.

8. A beloved pet dies of old age. You have very

fond memories of your pet and are reminded

of them every time you see a similar breed. 
Table 2. Bootstrapped pairwise comparisons between hues. We compared the frequencies of hue choices for each of the induced moods (i.e., joy, relaxation, fear, and sadness). The table shows the number of participants choosing a particular hue $(n)$, and percentage of participants (from total $N$ ) making this selection (\%). A common letter between two hues indicates that the pairwise comparison between those two hues was not significant. No letters in common between two hues indicates that the pairwise comparison was significant (i.e., these two hues were not chosen at the same frequency).

\begin{tabular}{|c|c|c|c|c|c|c|c|c|}
\hline \multirow[b]{2}{*}{ Hue } & \multicolumn{2}{|l|}{ Joy } & \multicolumn{2}{|c|}{ Relaxation } & \multicolumn{2}{|l|}{ Fear } & \multicolumn{2}{|l|}{ Sadness } \\
\hline & n (\%) & Letter & n (\%) & Letter & n (\%) & Letter & n (\%) & Letter \\
\hline Red & $4(18.2)$ & $a b$ & $3(12.0)$ & $a$ & $7(28.0)$ & $a$ & $4(16.7)$ & $a$ \\
\hline Orange & $3(13.6)$ & $a b$ & 4 (16.0) & $a$ & $0(0.0)$ & $a$ & $0(0.0)$ & $a$ \\
\hline Yellow & $11(50.0)$ & $a$ & $2(8.0)$ & $a$ & $0(0.0)$ & $a$ & $0(0.0)$ & $a$ \\
\hline Yellow-Green & $0(0.0)$ & $b$ & $5(20.0)$ & $a$ & $1(4.0)$ & $a$ & $1(4.2)$ & $a$ \\
\hline Green & $0(0.0)$ & $b$ & $2(8.0)$ & $a$ & $1(4.0)$ & $a$ & $0(0.0)$ & $a$ \\
\hline Green-Blue & $0(0.0)$ & $b$ & $3(12.0)$ & $a$ & $4(16.0)$ & $a$ & $1(4.2)$ & $a$ \\
\hline Blue & $1(0.05)$ & $b$ & $6(24.0)$ & $a$ & $2(8.0)$ & $a$ & $4(16.7)$ & $a$ \\
\hline Purple & $3(13.6)$ & $a b$ & $0(0.0)$ & $a$ & $4(16.0)$ & $a$ & $5(20.8)$ & $a$ \\
\hline Achromatic & $0(0.0)$ & $b$ & $0(0.0)$ & $a$ & $6(24.0)$ & $a$ & $9(37.5)$ & $a$ \\
\hline Total & $22(100)$ & & 25 (100) & & 25 (100) & & $24(100)$ & \\
\hline
\end{tabular}


Table 3. Frequencies of warm (red, orange, yellow, or yellow-green) vs. cool (green-blue or blue) hue choices in four induced mood conditions. Subscript letters indicate significant difference between conditions $(p<.050)$.

\begin{tabular}{lll}
\hline & Warm & Cool \\
\hline Joy & $18 \mathrm{a}$ & $1_{\mathrm{a}}$ \\
Relaxation & 14 & 9 \\
Fear & 8 & 6 \\
Sadness & 5 & 5 \\
\hline
\end{tabular}

